Koukichi Kurehara MD, ${ }^{*}$ Hideyuki Ohnishi MD, $\dagger$ Hajime Touho MD, $†$ Hitoshi Furuya MD, $\ddagger$ Takao Okuda MD $\ddagger$

\title{
Cortical blood flow response to hypercapnia during anaesthesia in Moyamoya disease
}

Cortical blood flow ( $C O B F$ ) was measured continuously by the laser-Doppler method to evaluate the effect of hypercapnia on cortical blood flow during ten surgical procedures in ten young patients (mean $\pm S D 9.3 \pm 6.4 \mathrm{yr}$ ) with Moyamoya disease. The CoBF was $42.8 \pm 13.4\left(\mathrm{ml} \cdot 100 \mathrm{~g}^{-1} \cdot \mathrm{min}^{-1}\right)$ during normocapnia $\left(\mathrm{PaCO}_{2}=39.0 \pm 2.4 \mathrm{mmHg}\right.$ ), and $38.7 \pm 14.4$ during hypercapnia $\left(\mathrm{PaCO}_{2}=47.1 \pm 2.5 \mathrm{~mm} \mathrm{Hg}\right.$ ). There was a decrease in CoBF with hypercapnia $(P<0.05)$ so that the normal CoBF response to hypercapnia was impaired during surgery in the patients with Moyamoya disease. He concluded that patients with Moyamoya disease have a precarious cerebral circulation and hypercapnia may be detrimental to the cortical circulation. This suggests that normocapnia is preferable to hypercapnia in patients with Moyamoya disease during anaesthesia.

Pendant dix interventions chirurgicales pratiquées chez dix jeunes patients (âge moyen 9,3 $\pm 6,4$ ans) souffrant de la maladie de Moyamoya, le débit sanguin cortical (DSCo) est mesuré continuellement par la méthode Laser-Doppler dans le but d'évaluer les effets de l'hypercapnie sur le débit sanguin cortical. Le DSCo $\left(\mathrm{ml} \cdot 100 \mathrm{~g}^{-l} \cdot \mathrm{min}^{-1}\right)$ est de 42,8 $\pm 13,4$ pendant la normocapnie ( $\mathrm{PaCO}_{2}=39,0 \pm 2,4 \mathrm{~mm} \mathrm{Hg}$ ) et de $38,7 \pm 14,4$ pendant l'hypercapnie $\left(\mathrm{PaCO}_{2}=47,1 \pm 2,5\right.$

\section{Key words}

ANAESTHESIA: neurosurgical;

BLOOD: flow;

BRAIN: blood flow, carbon dioxide tension; COMPLICATIONS: Moyamoya disease.

From the Departments of Anaesthesiology* and

Neurosurgery†, Osaka Neurological Institute, and the

Department of Anaesthesiologył, Nara Medical University.

This work was carried out in Department of

Anaesthesiology, Osaka Neurological Institute, Osaka, Japan. Address correspondence to: Dr. Koukichi Kurehara,

Department of Anaesthesiology, Nara Medical University,

Shijoucho, Kashihara, Nara 634, Japan.

Accepted for publication 24th May, 1993. $m m \mathrm{Hg}$ ). La baisse du débit pendant hypercapnie est signifcative $(P<0,05)$. Ce qui démontre que la réponse du débit sanguin cérébral est perturbée pendant la chirurgie de la maladie de Moyamoya. On conclut que cette maladie a une influence néfaste sur la circulation cérébrale pendant l'hypercapnie. Ceci suggère que dans la maladie de Moyamoya, la normocapnie est préférable à l'hypercapnie.

Moyamoya disease is a rare occlusive cerebrovascular disease. Angiographic findings may demonstrate progressive stenosis or occlusion of the terminal portions of the internal carotid artery and the origins of the anterior cerebral and middle cerebral arteries, abnormal vascular networks at the base of the brain, and several transdural anastomoses. The characteristic symptoms of the disease are transient ischaemic attacks (TIAs) causing hemiparesis or weakness of the limbs associated with hyperventilation when crying or exercising. ' However, the details of the pathophysiological mechanism remain uncertain.

Several surgical approaches have been reported to increase the blood supply to the ischaemic hemispheres, such as superficial temporal artery-middle cerebral artery (STA-MCA) anastomosis, ${ }^{1}$ encephalo-myo-synangiosis (EMS), ${ }^{2}$ and encephalo-duro-arterio-synangiosis (EDAS). ${ }^{3}$ Patients with Moyamoya disease have a precarious cerebral circulation. During surgery, it is considered to be important to preserve cerebral blood flow by controlling blood pressure and arterial carbon dioxide tension $\left(\mathrm{PaCO}_{2}\right)$.

Several $^{4-7}$ studies have evaluated the cerebrovascular $\mathrm{CO}_{2}$ reactivity in patients with Moyamoya disease. The $\mathrm{CO}_{2}$ reactivity is preserved in the hypocapnic state ${ }^{4-7}$ so that decreasing $\mathrm{PCO}_{2}$ will reduce cerebral blood flow in Moyamoya disease. However, the effect of hypercapnia on the cerebral circulation has not been evaluated in this disease.

In this study, we measured cortical blood flow (CoBF) continuously using the laser-Doppler method during 
TABLE I Patient summary

\begin{tabular}{|c|c|c|c|c|c|}
\hline Case No. & $\begin{array}{l}\text { Age } / \mathrm{Sex} \\
(y r)\end{array}$ & $\begin{array}{l}\text { Type of } \\
\text { onset }\end{array}$ & Clinical signs & $\begin{array}{l}\text { Duration from onset } \\
\text { to operation }\end{array}$ & $\begin{array}{l}\text { Operation } \\
\text { side }\end{array}$ \\
\hline 1 & $13 / F$ & $\mathrm{~T} 1 \mathrm{~A}$ & Mental retardation & $10 \mathrm{yr}$ & Rt. \\
\hline 2 & $S / F$ & TIA & No deficit & $1 \mathrm{yr}$ & Lt. \\
\hline 3 & $8 / F$ & TIA & Rt. hemiparesis & $1 \mathrm{yr}, 2 \mathrm{mo}$ & Rt. \\
\hline 4 & $16 / \mathrm{F}$ & TIA & No deficit & $5 \mathrm{yr}$ & Rt. \\
\hline 5 & $8 / \mathrm{F}$ & TIA & Quadniparesis & 3 уг & Rt. \\
\hline 6 & $8 / F$ & TIA & No deficit & $3 \mathrm{yr}$ & Lt. \\
\hline 7 & $3 / \mathrm{M}$ & TIA & No deficit & $3 \mathrm{mo}$ & Rt. \\
\hline 8 & $2 / \mathrm{M}$ & TIA & Rt. hemiparesis & $7 \mathrm{mo}$ & Rt. \\
\hline 9 & $7 / \mathrm{F}$ & TIA & No deficit & $1 \mathrm{yr}$ & Lt. \\
\hline 10 & $23 / F$ & TIA & Lt. hemianopsia & $11 \mathrm{yr}$ & Rt. \\
\hline
\end{tabular}

F: female, M: male, TIA: transient ischaemic attack, Rt.: right, Lt.: left.

TABLE II Physiological data during normocapnia and hypercapnia

\begin{tabular}{lcr}
\hline & Normocapnia & Hypercapnia \\
\hline $\mathrm{HR}(\mathrm{bpm})$ & $95.7 \pm 18.2$ & $96.0 \pm 16.6$ \\
$\mathrm{BP}(\mathrm{mmHg})$ & $99.4 \pm 14.6$ & $101.1 \pm 14.5$ \\
$\mathrm{PaCO}_{2}(\mathrm{mmHg})$ & $39.0 \pm 2.4$ & $47.1 \pm 2.5^{*}$ \\
$\mathrm{PaO}_{2}(\mathrm{mmHg})$ & $190.8 \pm 41.1$ & $171.1 \pm 19.6$ \\
\hline
\end{tabular}

HR: heart rate, BP: blood pressure.

${ }^{*} P<0.01$ versus normocapnia.

STA-MCA anastomosis, and the effect of hypercapnia on CoBF in Moyamoya disease was evaluated.

\section{Methods}

Institutional Ethics Committee approval and informed consent were obtained. Fourteen young patients (three male and seven female ranging in age from 2 to 23 year, mean $\pm \mathrm{SD} 9.3 \pm 6.4 \mathrm{yr}$ ) with Moyamoya disease were included in the study. The diagnosis had been established by bilateral carotid angiography in all patients. All patients had ischaemic cerebrovascular symptoms and signs without intracranial haemorrhage (Table I).

Ten STA-MCA anastomoses with EMSs were performed in these patients. After premedication with monosodium trichlorethyl phosphate $\left(80-100 \mathrm{mg} \cdot \mathrm{kg}^{-1} \mathrm{po}\right)$ or hydroxyzine $\left(1 \mathrm{mg} \cdot \mathrm{kg}^{-1} \mathrm{im}\right)$, anaesthesia was induced by inhalation of sevoflurane (4-5\%) nitrous oxide, and oxygen, or by thiopentone $\left(4-5 \mathrm{mg} \cdot \mathrm{kg}^{-1} \mathrm{i}\right)$. After administration of vecuronium $\left(0.1 \mathrm{mg} \cdot \mathrm{kg}^{-1} i v\right)$, the trachea was intubated, and the lungs were mechanically ventilated. Additional doses of vecuronium or pancuronium were given when necessary. The patients received midazolam 1-2.5 mg and fentanyl $4.0-10.7 \mu \mathrm{g} \cdot \mathrm{kg}^{-1}$ in addition to oxygen and nitrous oxide 33:67. Temperature, oxygen saturation, end-tidal $\mathrm{CO}_{2}$, blood pressure, and heart rate by ECG were monitored during the operation. A radial artery cannula was inserted for sampling of blood gases (ABL3, Radiometer, Denmark).
The CoBF was measured by the laser-Doppler method. The principles of measurement of tissue surface blood flow with a laser-Doppler flowmeter have been previously described. ${ }^{8-11}$ In brief, the laser-Doppler method is based on the principle that light scattered by moving red blood cells experiences a frequency shift that is proportional to the mean velocity of red cells. Electrical signals generated by the photodetector contain information about the frequency, which is related to the blood cell velocity, and the power, which is related to the blood volume. Blood flow is computed as:

(blood flow $)=($ blood volume $) \cdot($ blood velocity $)$

The laser-Doppler flow value is the microcirculatory blood flow within an illuminated tissue volume of about $1 \mathrm{~mm}^{3}$. The laser-Doppler flowmeter (ALF21, Advance, Tokyo) used in this study had a diode laser beam with an optical output power of $2 \mathrm{~mW}$ at the probe and a wavelength of $780 \mathrm{~nm}$. The measurement range is $0-100$ $\mathrm{ml} \cdot 100^{-1} \cdot \mathrm{min}^{-1}$ of CBF.

After craniotomy, the dura was opened and the site of anastomosis was chosen. While the STA branch was harvested from the skin flap, a flat probe was placed on the cortex, avoiding surface vascular channels, for continuous monitoring of $\mathrm{CoBF}$ in the sampling area. Measurements were performed at eight sites in the parietal lobes, and two sites in the frontal lobes. Ventilation was controlled to maintain end-tidal $\mathrm{CO}_{2}$ at about $40 \mathrm{mmHg}$ and normocapnic CoBF was measured. After a steady state recording was obtained during normocapnia, ventilation was controlled to maintain end-tidal $\mathrm{CO}_{2}$ at about 45-50 $\mathrm{mmHg}$ while monitoring oxygen saturation. Blood pressure and blood gases were measured during normocapnia and hypercapnia. Electrical signals from the laserDoppler flowmeter were recorded continuously on a polygraph (Nihon Kohden, Tokyo).

Data analysis was performed with a computerized statistical analysis package (Stat Flex, View Flex Inc., 
TABLE III Cortical blood flow during normocapnia and hypercapnia, and $\mathrm{CO}_{2}$ reactivity

\begin{tabular}{|c|c|c|c|}
\hline $\begin{array}{l}\text { CoBF at normocapnia } \\
\left(\mathrm{mt}^{-1} \cdot 100 \mathrm{~g}^{-1} \cdot \mathrm{min}\right)\end{array}$ & $\begin{array}{l}\text { CoBF at hypercapnia } \\
\left(\mathrm{mt}^{-1} \cdot 100 \mathrm{~g}^{-1} \cdot \min \right)\end{array}$ & $\begin{array}{l}\triangle C o B F \cdot \triangle P C O_{2}^{-1} \\
\left(\mathrm{ml}^{-1} \cdot 100 \mathrm{~g}^{-1} \cdot \mathrm{min}^{-1} \cdot \mathrm{mmHg}\right)\end{array}$ & $\begin{array}{l}\triangle \% \mathrm{CoBF} \cdot \triangle P C \mathrm{CO}_{2}^{-1} \\
\left(\%^{-l} \cdot \mathrm{mmHg}\right)\end{array}$ \\
\hline $42.8 \pm 13.4$ & $38.7 \pm 14.4^{*}$ & $-0.64 \pm 0.82$ & $-1.57 \pm 1.59$ \\
\hline
\end{tabular}

CoBF: cortical blood flow.

$* P<0.05$ versus normocapnia.

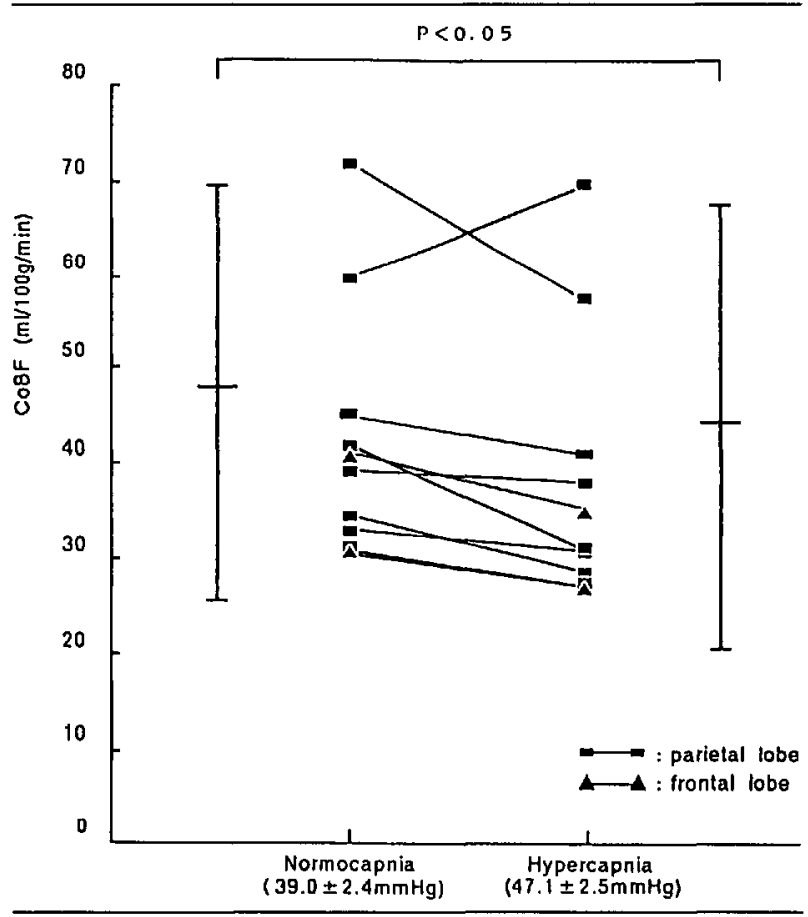

FIGURE \ COBF measured by the laser-Doppler method during normocapnia and hypercapnia. Measurements were performed at eight sites in the parietal lobes, and two sites in the frontal lobes. There was a decrease in $\mathrm{CoBF}$ during hypercapnia $(P<0.05)$.

Tokyo). Normality of distribution of the data obtained during normocapnia and hypercapnia was analyzed. In the absence of a normal distribution the data were analyzed using the Wilcoxon test. When normal distribution was confirmed during each state, analysis was with Student's paired $t$ test. All data were expressed as mean $\pm \mathrm{SD}$, a $P<0.05$ was considered significant.

\section{Results}

The summarized data of all patients are shown in Table I. Anaesthesia and surgery were uneventful in all patients. There were no differences in blood pressure, heart rate or $\mathrm{PaO}_{2}$ between the normocapnic and hypercapnic state (Table II). The $\mathrm{PaCO}_{2}$ was $39.0 \pm 2.4 \mathrm{mmHg}$ during normocapnia and $47.1 \pm 2.5 \mathrm{mmHg}$ during hypercapnia $(P<0.001)$. The CoBF was $42.8 \pm 13.4$ $\left(\mathrm{ml} \cdot 100 \mathrm{~g}^{-1} \cdot \mathrm{min}^{-1}\right)$ during normocapnia, with individ-

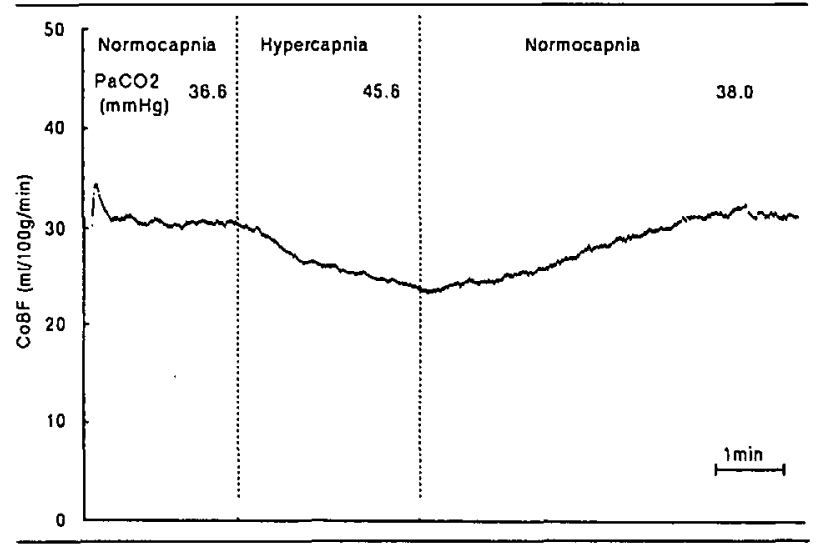

FIGURE 2 Continuous recording of CoBF in a typical case. CoBF was gradually decreased during hypercapnia.

ual variations (Figure 1). During hypercapnia, CoBF decreased to $38.7 \pm 14.4(P<0.05$, Table III, Figure 1). The ratio of $\mathrm{CoBF}$ change versus change in $\mathrm{PaCO}_{2}$ (CoBF. $\mathrm{PaCO}_{2}{ }^{-1}: \mathrm{ml} \cdot 100 \mathrm{~g}^{-1} \cdot \mathrm{min}^{-1} \cdot \mathrm{mmHg}^{-1}$ ) was $-0.64 \pm 0.82$. A continuous recording of the typical case is shown in Figure 2.

\section{Discussion}

Several studies of cerebral blood flow (CBF) in Moyamoya disease have been reported ${ }^{4-7,12,13}$ using argon inhalation, ${ }^{4,12}{ }^{133} \mathrm{Xe}$ clearance $^{5-7}$ and thermal diffusion methods. ${ }^{13}$ However, many of these measurements are complicated and intermittent assessments of flow except for the thermal diffusion method. ${ }^{13}$ In the present study, the laser-Doppler method was used for measurement of CoBF which allows continuous measurement, is noninvasive and can be performed rapidly at the time of operation. The laser-Doppler flowmeter has been used to measure local CBF both in experimental animals ${ }^{8-10}$ and in human patients during surgery. "Skarphedinsson $e t$ $a l{ }^{8}$ compared the laser-Doppler with the hydrogen clearance method in rats, and found a good correlation between the values of local CBF obtained. Other studies ${ }^{9,10}$ have reported similar results. Thus, the laser-Doppler flowmeter may be used to measure microcirculatory blood flow of the cerebral cortex quantitatively.

The cerebral circulation in patients with Moyamoya 
disease has been studied by various methods ${ }^{4-7,12,13}$ and is sluggish. Karasawa et al. ${ }^{12}$ measured CBF using argon inhalation in 17 children with Moyamoya disease, and divided them into three groups according to the neurological manifestations of transient ischaemic attack, minor and major stroke. Cerebral blood flow was decreased in all three groups, especially in the group with major strokes, compared with normal children. Takeuchi et al. ${ }^{13}$ measured $\mathrm{CoBF}$ by thermal diffusion in 12 young patients with Moyamoya disease during STA-MCA anastomosis performed under neuroleptanaesthesia. They reported that the mean pre-bypass $\mathrm{CoBF}$ was $39.4 \pm 13.0 \mathrm{ml} \cdot 100$ $\mathrm{g}^{-1} \cdot \min ^{-1}$ in the parieto-temporal regions during normocapnia, with individual variation. In our study, the mean CoBF was $42.8 \pm 13.4 \mathrm{ml} \cdot 100 \mathrm{~g}^{-1} \cdot \mathrm{min}^{-1}$ by the laser-Doppler method, again with interindividual variation. The variation may be characteristic of $\mathrm{CoBF}$ in Moyamoya disease.

Several studies ${ }^{4-7}$ have reported the cerebrovascular $\mathrm{CO}_{2}$ reactivity in patients with Moyamoya disease. Carbon dioxide reactivity is preserved in the hypocapnic state. ${ }^{4-7}$ Uemura et al. ${ }^{6}$ measured regional cerebral blood flow in patients with Moyamoya disease using the ${ }^{133} \mathrm{Xe}$ intracarotid injection. During hypercapnia induced by $5 \%$ $\mathrm{CO}_{2}$ inhalation, regional cerebral blood flow was unchanged or decreased slightly. Using the ${ }^{133} \mathrm{Xe}$ inhalation in patients with Moyamoya disease regional cerebral blood flow was increased in the temporo-occipital regions and was unchanged or decreased in the frontal region by $5 \% \mathrm{CO}_{2}$ inhalation. ${ }^{7}$ In the present study, $\mathrm{CoBF}$ was decreased during hypercapnia. In Moyamoya disease, the cortical arteries in the fronto-parietal lobes, which are fed mainly by the severely stenosed middle and anterior cerebral arteries or collateral pathways through the abnormal vascular network, seem to be either in a state of full dilatation or high vascular resistance due to proximal occlusion or severe stenosis. Thus they may not be able to dilate further during hypercapnia. ${ }^{7}$ Furthermore, in Moyamoya disease, stenosis or occlusion of the internal carotid, middle cerebral and anterior cerebral arteries precedes that of the posterior cerebral artery. Since the temporo-occipital regions are fed mainly by the posterior cerebral artery, $\mathrm{CO}_{2}$ reactivity is considered to be relatively preserved in these regions. Under such conditions, greater cerebral vasodilatation in the region with relatively preserved $\mathrm{CO}_{2}$ reactivity could divert blood away from regions with impaired $\mathrm{CO}_{2}$ reactivity. The decrease of cerebral blood flow during hypercapnia in this study may be explained by this "intracerebral steal" effect. Thus, both hypocapnia and hypercapnia may be detrimental to the cerebral circulation in Moyamoya disease. When managing patients with Moyamoya disease during surgery, normocapnia is preferable to hypercapnia.
Increasingly, patients with Moyamoya disease are treated surgically to improve the cerebral circulation, and several cases of neurological deterioration after general anaesthesia have been reported. ${ }^{14,15}$ According to our results in patients with Moyamoya disease, normocapnia is preferable to hypercapnia during surgery.

\section{References}

1 Karasawa J, Kikuchi H, Furuse S, Kawamura J, Sakaki T. Treatment of moyamoya disease with STA-MCA anastomosis. J Neurosurg 1978; 49: 679-88.

2 Karasawa J, Kikuchi H, Furuse S, et al. A surgical treatment of Moyamoya disease "Encephalo-Myo-Synangiosis." Neurol Med Chir (Tokyo) 1977; 17: 29-37.

3 Matsushima Y, Fukai N, Tanaka $K$, et al. A new surgical treatment of moyamoya disease in children: a preliminary report. Surg Neurol 1981; 15: 313-20.

4 Karasawa J, Kikuchi H, Nagata I, et al. Cerebral hemodynamics in moyamoya disease. Significance of cerebral blood flow in relation with the changes in arterial $\mathrm{CO}_{2}$ tension. Neurol Med Chir (Tokyo) 1986; 26: 695-700.

5 Ishii $R$. Hemodynamic evaluation after surgical treatments for moyamoya disease. Kawasaki Medical Journal, 1986; 12: $51-60$.

6 Uemura K, Yamaguchi K, Kojima S, et al. Regional cerebral blood flow on cerebro-vascular "moyamoya" disease. Study by ${ }^{133} \mathrm{Xe}$ clearance method and cerebral angiography. No To Shinkei 1975; 27: 385-93.

7 Takeuchi S, Tanaka R, Ishii R, Tsuchida T, Kobayashi K, Arai $H$. Cerebral hemodynamics in patients with moyamoya disease. A study of regional cerebral blood flow by the ${ }^{133} \mathrm{Xe}$ inhalation method. Surg Neurol 1985; 23 : 468-74.

8 Skarphedinsson JO, Hårding H, Thorén P. Repeated measurements of cerebral blood flow in rats. Comparisons between the hydrogen clearance method and laser Doppler flowmetry. Acta Physiol Scand 1988; 134: $133-42$.

9 Haberl RL, Heizer ML, Marmarou A, Ellis EF LaserDoppler assessment of brain microcirculation: effect of systemic alterations. Am J Physiol 1989; 256: H1247-54.

10 Saeki Y, Sato A, Sato Y, Trzebski A. Effects of stimulation of cervical sympathetic trunks with various frequencies on the local cortical cerebral blood flow measured by laser Doppler flowmetry in the rat. Jpn J Physiol 1990; 40: 15-32.

11 Rosenblum BR, Bonner RF, Oldfield EH. Intraoperative measurement of cortical blood flow adjacent to cerebral AVM using laser Doppler velocimetry. J Neurosurg 1987; 66: 396-9.

12 Karasawa J, Kikuchi H, Kuriyama Y, et al. Cerebral hemodynamics in "moyamoya" disease. II. Measurements of cerebral circulation and metabolism by use of the argon 
desaturation method in pre- and post-neurosurgical procedures. Neurol Med Chir (Tokyo) 1981; 21: 1161-8.

13 Takeuchi S, Kikuchi H, Karasawa J, Yamagata S, Nagata I. Regional cortical blood flow during extra-intracranial bypass surgery in young patients with moyamoya disease. Neurol Med Chir (Tokyo) 1989; 29: 10-4.

14 Sumikawa $K$, Nagai $H$. Moyamoya disease and anesthesia (Letter). Anesthesiology 1983; 58: 204-5.

15 Yoshii Y. Follow-up study of the "Moyamoya." No To Shinkei 1976; 29: 61-4. 